\title{
Thermal Study of Gallium Nitride - Metal Contact
}

\author{
Saeed S. Al-Ameer \\ Department of Physics, Faculty of Science, \\ King Abdulaziz University \\ P.O. Box 80203, Jeddah 21589, Saudi Arabia \\ ssaameer@yahoo.com
}

\begin{abstract}
GaN films are prepared by MOCVD method on a sapphire substrate. The sample is n-type an semiconductor of $0.5 \mu \mathrm{m}$ thickness and carriers concentration $2.2 \times 10^{19} \mathrm{~cm}^{-3}$. Metal contacts are prepared by evaporation of metals on $\mathrm{GaN}$ films. I-V characteristics are carried out under vacuum in the temperature rang from 90 to $300 \mathrm{~K}$. There is a departure from the nonlinear behavior of the current to a linear one as temperature increases due to the sample series resistance. The saturation current is found to be $8.3 \times 10^{-7} \mathrm{~A}$ at room temperature; then, it increases with temperature. At room temperature, the barrier height at zero- bias and the flat band barrier height are calculated at different temperature and they are found to be $0.66 \mathrm{eV}$ and $0.86 \mathrm{eV}$, respectively. Moreover, the ideality factor has been calculated at different temperature; it' increases with decreasing temperature and it is equal to 1.26 at room temperature. The serial resistant is found to be to $64 \Omega$ at room temperature.
\end{abstract}

Keywords: Ideality factor, barrier height, $\mathrm{I}-\mathrm{V}_{\mathrm{T}}$ measurements.

\section{Introduction}

Recently, some researchers ${ }^{[1]}$ have shown that the barrier height of GaN diodes could be abased by dipole formation of hydrogen atoms (hydrogen bonds). Moreover, another researchers ${ }^{[2]}$ have demonstrated that these barriers are decreased by annealing. In general, Gallium Nitride $(\mathrm{GaN})$ is a wide direct-band gap semiconductor ${ }^{[3]}$ which has a broad range of electrical applications especially, in high temperature electronic devices, optoelectronic and high-power devices. Intensive activities on high-power devices, short-wavelength light (blue, violet) 
emitting diodes (LEDs), and laser diodes (LDs) ${ }^{[3]}$ have been done. The current-voltage I-V and capacitance- voltage $\mathrm{C}-\mathrm{V}$ characteristics for $\mathrm{n}$ type $\mathrm{GaN}$ films, were carried out ${ }^{[4]}$. These films were grown by molecular beam epitaxial (MBE) method on a sapphire substrate. Their film was $1 \mu \mathrm{m}$ thick and doped with $\mathrm{Si}$ at a concentration of $1 \times 10^{-7}$ $\mathrm{cm}^{-3}$. Circular contacts were gold with diameters of $100 \mu \mathrm{m}$ evaporated on the surface of the film. The Barrier height, built-in potential and carrier concentration from $\mathrm{C}-\mathrm{V}$ measurement were determined as $1.7 \mathrm{eV}$, $1.6 \mathrm{~V}$ and $0.9 \times 10^{17} \mathrm{~cm}^{-3}$ respectively ${ }^{[4]}$.

An experimental investigation of the Pt-n-GaN Schottky diodes has been carried out ${ }^{[5]}$. Epitomical layers of $n-G a N$ were grown on (0001) sapphire substrate by molecular beam piracy. An AlN buffer layer whose thickness is $725 \mathrm{~A}$ was grown at an sapphire substrate at $800^{\circ} \mathrm{C}$. The doping density in the GaN film was deduced to be $2 \times 10^{17} \mathrm{~cm}^{-3}$. Schottky barrier height, determined from the current-voltage and capacitance-voltage measurements, was close to $1.10 \mathrm{eV}^{[5]}$.

$\mathrm{I}-\mathrm{V}$ and $\mathrm{C}-\mathrm{V}$ characteristics of Schottky diodes, fabricated on different $\mathrm{GaN}$ films, are investigated ${ }^{[6]}$. They were grown by metal organic chemical vapor deposition (MOCVD) on sapphire substrates. Schottky contacts were fabricated by thermally evaporation gold ( $\mathrm{Au}$ ) films onto the sample in vacuum. The diameter of the Au spot was 400 $\mu \mathrm{m}$. Ohmic contacts were formed by thermally evaporated indium $(800$ $\mathrm{A}^{\circ}$ ) followed by 4 min of $350^{\circ} \mathrm{C}$ annealing in a high-purity $\mathrm{N}_{2}$ at ambient. The carrier concentration of the sample was $3.2 \times 10^{17} \mathrm{~cm}^{3}$. The barrier height and the ideality factor reported for this sample are $0.913 \mathrm{eV}$ and 1.30 respectively ${ }^{[6]}$.

Also, the current-voltage characteristics of Au/n-GaN Schottky diodes in the temperature range $80-300 \mathrm{~K}$ are determined ${ }^{[7]}$. The GaN samples were $4 \mu \mathrm{m}$ thick epitaxial layer grown by metal organic chemical vapor deposition on (0001) sapphire substrate with a carrier concentration of about $10^{17} \mathrm{~cm}^{-3}$. The metal contacts were deposited by vacuum evaporation at a starting base pressure of $2 \times 10^{-6}$ Torr. By current-voltage methods; the barrier height, was determined ${ }^{[7]}$ at room temperature and it was evaluated to be $0.98 \mathrm{eV}$ but it was found to be $1.02 \mathrm{eV}$ by the capacitance-voltage technique. The built-in potential and the ionized donor concentration of $\mathrm{GaN}$ were determined to be $0.925 \mathrm{~V}$ and $7.75 \times 10^{16} \mathrm{~cm}^{-3}$ respectively ${ }^{[7]}$. By current-voltage methods; the 
barrier height, was determined ${ }^{[7]}$ at room temperature and it was evaluated to be $0.98 \mathrm{eV}$ but it was found to be $1.02 \mathrm{eV}$ by the capacitance-voltage technique. The built-in potential and the ionized donor concentration of $\mathrm{GaN}$ were determined to be $0.925 \mathrm{~V}$ and $7.75 \times$ $10^{16} \mathrm{~cm}^{-3}$ respectively ${ }^{[7]}$.

The temperature dependence of I-V curves of GaN Schottky diodes have been studied ${ }^{[8]}$. The GaN sample was grown by metal organic chemical vapor deposition (MOCVD) on sapphire with $1.3 \mu \mathrm{m}$ thick the carrier concentration was $1.4 \times 10^{16} \mathrm{~cm}^{-3}$. Ohmic contacts were formed as $\mathrm{Ti} / \mathrm{Al} / \mathrm{Ni} / \mathrm{Au}$ and they were annealed at $850^{\circ} \mathrm{C}$. For $\mathrm{Ni} / \mathrm{Au} \mathrm{GaN}$ Schottky diodes have a layout of circular dots. The calculated barrier height by $\mathrm{C}-\mathrm{V}$ technique at room temperature was $1.17 \mathrm{~V}$. The ideality factor was very close to the unity and has a value of $1.05^{[8]}$. Some investigators ${ }^{[9]}$ have reported two distinct activation energies 0.39 and $0.81 \mathrm{eV}$ for undoped $\mathrm{GaN}$ film deposited on degenerate silicon ( $\mathrm{Si}$ ) substrate by reactive $\mathrm{rf}$ sputtering .

\section{Experimental Work}

\section{Contact Preparation}

In this work, the n-GaN wafer, which is doped by silicon, is used. This wafer is $0.5 \mu \mathrm{m}$ thick layer and is grown by metal organic chemical vapor deposition MOCVD method on sapphire substrate. Its carrier concentration is about $2.2 \times 10^{19} \mathrm{~cm}^{-3}$. This sample was supplied by the manufacturer (ATMI company). Before making the contact on the sample, we cleaned it, first, by soaking in methanol within an ultrasonic cleaner. It is agitated for 10 minutes followed by putting it into a dilute $\mathrm{HCl}$ and then rinsed with deionized water. After that, the sample is dipped in $\mathrm{HCl}$ : $\mathrm{HNO} 3$ solution with $(3: 1)$ and then rinsed with deionized water. Edward 306 vacuum coating unit is used for the evaporation of the metal on the GaN wafer sample. Molybdenum evaporation boats are used to evaporate gold. Coating units consist of rotary and oil diffusion pump to evacuate vacuum champer (bell jar) to about $10^{-5}$ Toor. The system is, also, equipped by two vacuum gauges; Penning and Pirani to measure the vacuum in the champers. There are two filament holders that maintain heat. A substrate mask, about $20 \mathrm{~cm}$ diameter, is put above the filament holders. This mask is made of aluminum which contains holes of $2 \mathrm{~mm}$ diameter to make gold contacts. Shutter (either, mechanical or electrical) 
can be used to prevent vapor between the source and substrate as desire. Quartz crystal is, usually, put inside the bell jar to measure and to control the deposition rate and the thickness.

\section{Current-Voltage Measurements}

The current-voltage measurements are carried out by using hp 4140B unit with voltmeter, ammeter and power supply. The sample is put inside a cryostat which connected to temperature with a temperature controller under vacuum system. This cryostat is used to study the I-V behavior as a function of temperature. The bulk diagram is shown in Fig. 1. A specially made probe is used to make the electrical contacts with the sample (deposited metals). The electrodes (Graphite) were attached to flexible springs in order to provide a good mechanical contact. This probe is maintained inside the cryostat. Data is collected at six fixed temperatures namely $90 \mathrm{~K}, 120 \mathrm{~K}, 160 \mathrm{~K}, 200 \mathrm{~K}, 220 \mathrm{~K}$ and $300 \mathrm{~K}$. The cryostat is evacuated up to pump pressure $10^{-5}$ Torr.

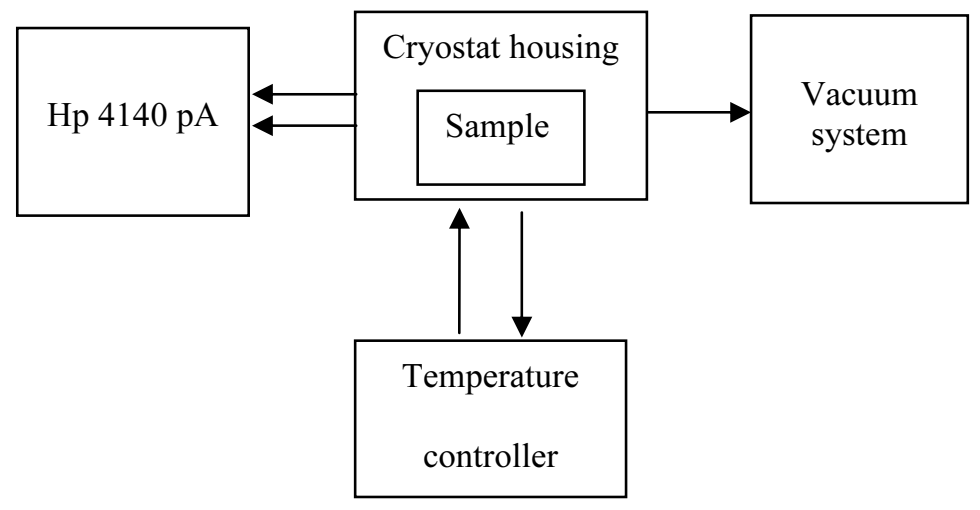

Fig. 1. Schematic diagram of the circuit.

\section{Results and Discussion}

The characteristics $\mathrm{I}-\mathrm{V}_{\mathrm{G}}$ is measured by using hp $4140 \mathrm{~B}$ system, in the temperature range from room temperature down to $90 \mathrm{~K}$ under, $10^{-5}$ Torr, vacuum. For n-type GaN sample, these I-V data are shown in Fig. 2. Which shows the $I-V_{G}$ measurements at different temperatures. From the data in this figure, one can conclude that the contact of Au with an ntype $\mathrm{GaN}$ acts as rectifying junction at low temperatures. It is, also, shown a departure from nonlinear behavior of the current to a linear one 
as temperature increases. This is, likely, due to the presence of a resistance connected in series with the sample. Moreover, there are two regions in the figure. The first, which is at low voltage, is governed by thermionic emission and the latter is assumed to be due to some mechanisms other than thermionic emission ${ }^{[7]}$. From this figure, one can estimate many of the diode parameters; e.g. the barrier height $\left(\varphi_{\mathrm{b}}\right)$, the ideality factor $(n)$, and the series resistance $\left(R_{S}\right)$.

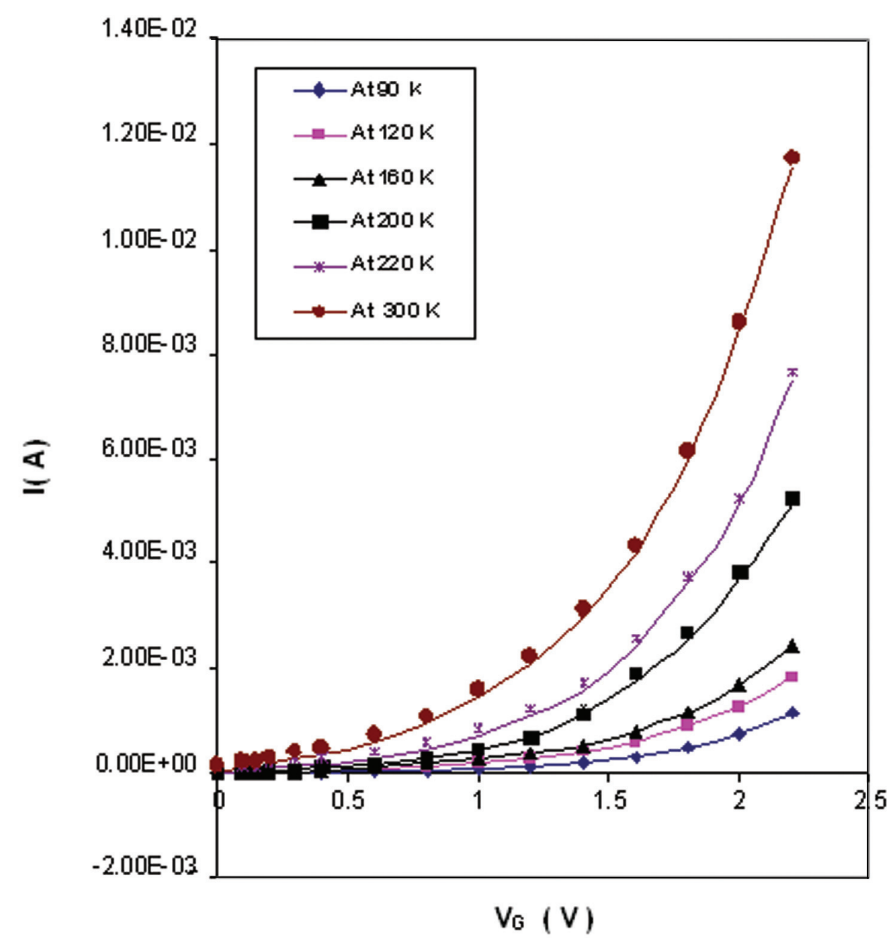

Fig. 2. Current various forward voltage of Au-GaN contact.

The $\mathrm{I}-\mathrm{V}_{\mathrm{G}}$ relationship under thermo-ionic emission theory is given by ${ }^{[8]}$

$$
I=I_{s}\left\lfloor\exp \left(\frac{q \mathrm{VG}_{\mathrm{G}}}{n k T}-1\right)\right\rfloor
$$

Where $\mathrm{n}$ is the ideality factor ${ }^{[8]}$, and $\mathrm{I}_{\mathrm{S}}$ is the saturation current given by:

$$
I_{s}=A A * T^{2} \exp \left\lfloor\frac{-q \phi_{b 0}}{k T}\right\rfloor
$$

Where $\mathrm{A}$ is the contact area, $\mathrm{q}$ is the electron charge, $\mathrm{T}$ is the temperature in Kelvin, $\mathrm{A}^{*}$ is the effective Richardson constant for thermionic 
emission, $\mathrm{k}$ is the Boltzmann constant, and $\varphi_{\mathrm{b} 0}$ is the zero-bias barrier height.

If the applied voltage $V_{G}$ is by far much than $k T / q$, then the exponential term in above equation (1) dominates, and the current, I, can be approximated as

$$
I=I_{s} \exp \left(\frac{q \mathrm{~V} \mathrm{G}_{\mathrm{G}}}{n k T}\right)
$$

In the following, we discuss how to determine $n, I_{s}, \varphi_{b}$, and $R_{S}$ from our experimental data of the forward $\left(I-V_{G}\right)$ characteristics at a certain temperature.

Firstly, to estimate the ideality factor $n$, one can use equation (3) after some logic modifications as:

$$
n=\frac{q}{k T} \frac{d \mathrm{~V}_{\mathrm{G}}}{d(\ln I)}
$$

Where $d V / d \ln I$ is the inverse of the slope in the linear region (1) of Fig. 3 . This inverse is about 1.26 at room temperature. Figure 4 shows the dependence between Ln I and the forward voltage at different temperatures in which the ideality factor can be deferred at different temperature as shown in Fig. 4. From this figure, one can notice that the ideality factor $\mathrm{n}$ decreases with increasing temperature. This is in good agreement with the thermo-ionic emission theory ${ }^{[10]}$. Tunneling and recombination currents, also, increase with temperature, but the thermoionic emission current increases more rapidly than they do. Another possible reason is if temperature is increased, it may anneal the contact and enhances its electrical properties.

The saturation current $\left(\mathrm{I}_{\mathrm{s}}\right)$ can be determined by extrapolating the linear region (1) in Fig. 3. At room temperature, it's value equal to 8.3 $\times 10^{-7} \mathrm{~A}$. The saturation current is increased with increasing temperature and that is, probably, due to the tunneling current.

The zero-bias barrier height $\varphi_{\mathrm{b} 0}$ can be calculated using the theoretical value of the Richardson constant $\left(26 \mathrm{~A}-\mathrm{cm}^{-2} \mathrm{~K}^{-2}\right)^{[7]}$ in equation (2). It can be modified to give zero-bias barrier height directly as ${ }^{[10]}$

$$
\varphi_{b 0}=\frac{k T}{q} \ln \left(\frac{A^{*} T^{2}}{J_{s}}\right)
$$




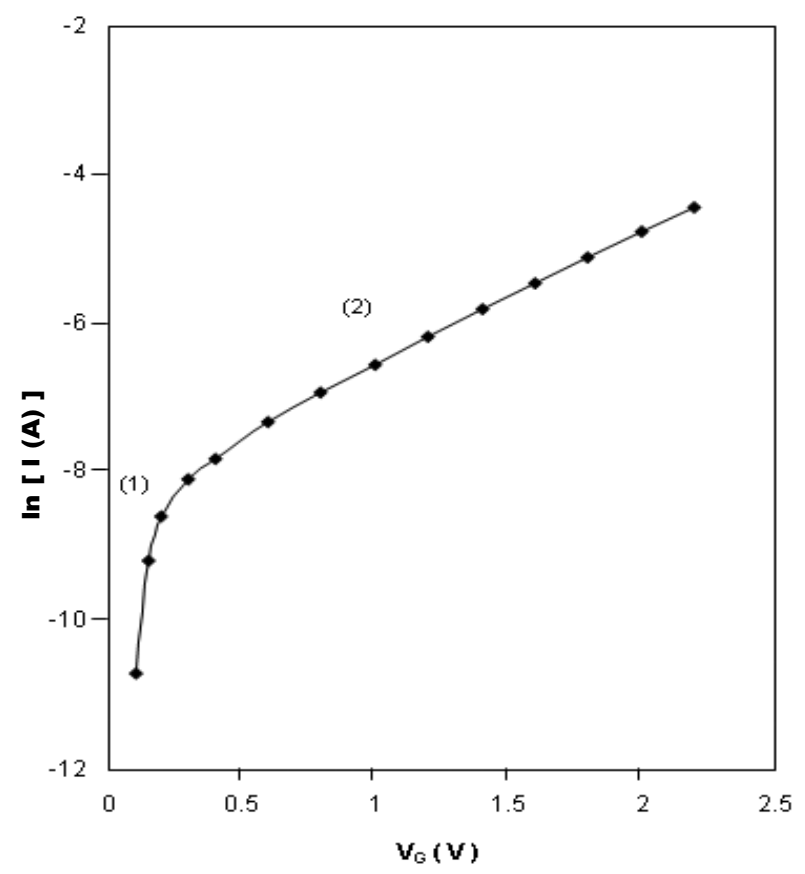

Fig. 3. In I various forward voltage for Au-GaN contact at room temperature.

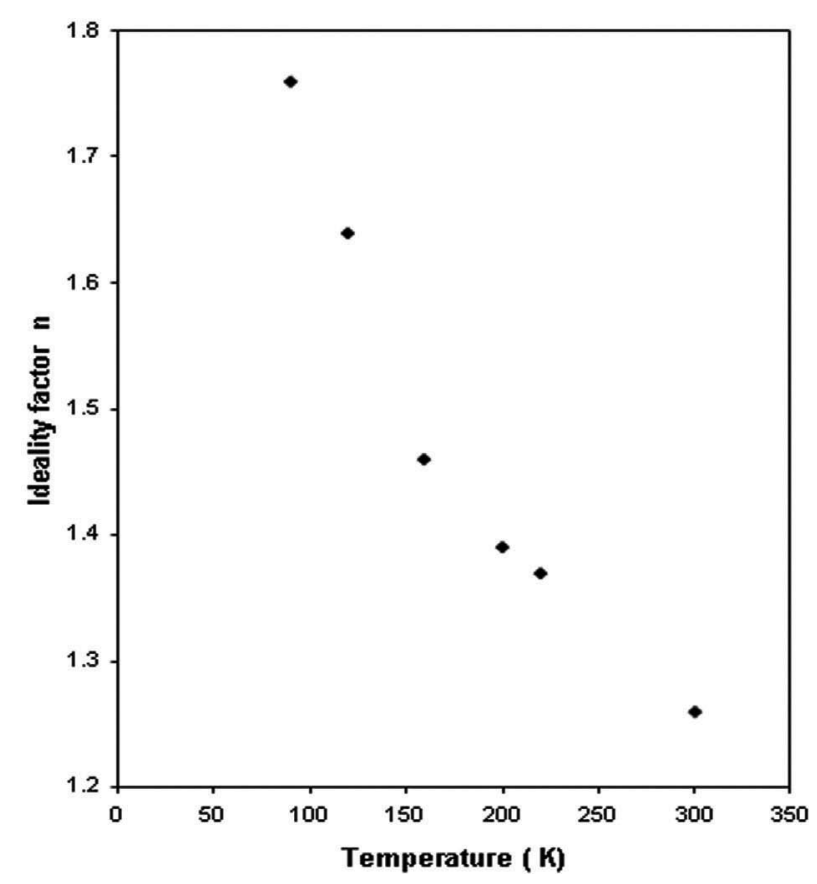

Fig. 4. Variation of the ideality factor $n$ with temperature of Au-GaN contact. 
Where $J_{\mathrm{s}}\left(=I_{\mathrm{S}} / \mathrm{A}\right)$ is the current density Barrier height given by this method is very sensitive for the saturation current. Existences of current component than the thermion emission led to decreasing the value of barrier height. It is slightly increased with increasing temperature as shown in Fig. 5. Also, the flat band barrier height $\varphi_{b F}$, can be obtained by using the following equation ${ }^{[7]}$,

$$
\varphi_{\mathrm{bF}}=\mathrm{n} \varphi_{\mathrm{b} 0}-(\mathrm{n}-1)\left(\mathrm{E}_{\mathrm{C}}-\mathrm{E}_{\mathrm{F}}\right)
$$

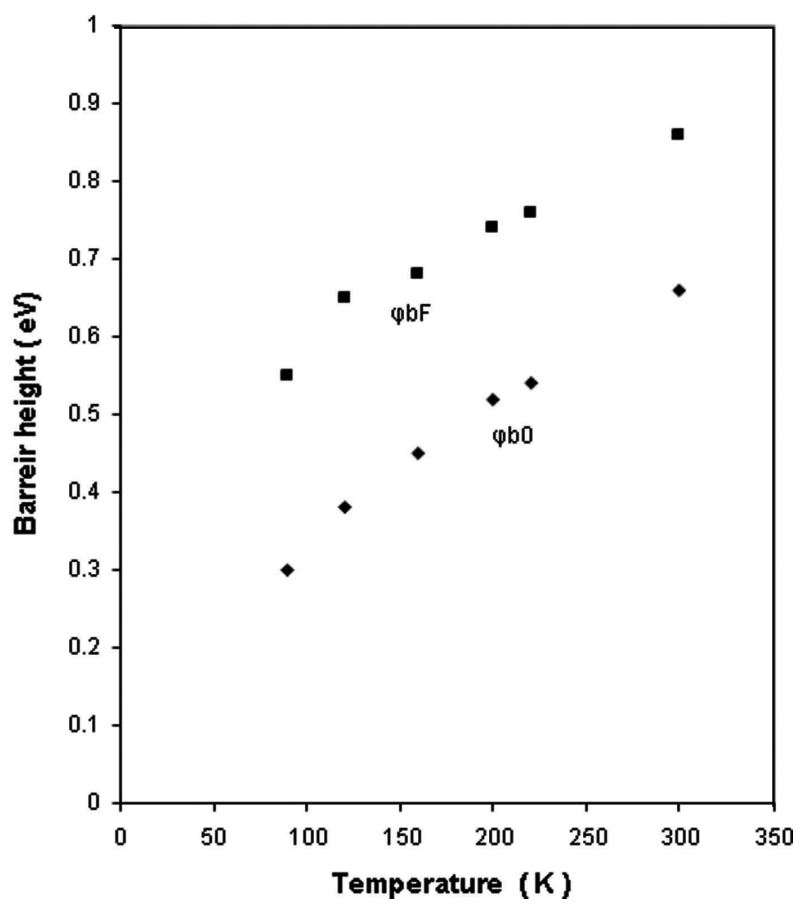

Fig. 5. Variation of the barrier height with temperature of Au-GaN contact.

Where $\mathrm{E}_{\mathrm{F}}$ is the Fermi energy and $\mathrm{E}_{\mathrm{C}}$ is the conduction band energy, so:

$$
\mathrm{E}_{\mathrm{c}}-\mathrm{E}_{\mathrm{F}}=\frac{k T}{q} \ln \left(\frac{N_{C}}{N_{D}}\right)
$$

Where $\mathrm{N}_{\mathrm{C}}$ is the effective density-of- states in the conduction band and $\mathrm{N}_{\mathrm{D}}$ is the donor concentration.

$\mathrm{N}_{C}$ changes with temperature (Assuming $\mathrm{N}_{\mathrm{D}}$ and the effective mass $\mathrm{m}_{\mathrm{e}}{ }^{*}$ does not change with temperature) according to the relation ${ }^{[7]}$ : 


$$
N_{c}\left(\mathrm{~cm}^{-3}\right)=2 \times 10^{18}\left(\frac{T}{300}\right)^{3 / 2}
$$

Then, we can determine the flat barrier height $\varphi_{b F}$ by using equation (6), as shown in Fig. 5. One cane notice that the barrier height $\varphi_{\mathrm{bF}}$ increases with temperature. In Fig. 3 the voltage drop is due to the contact interface and the series resistance of the GaN wafer after the depletion region. Equation 1 can be written in the terms of the voltage drop due to the series resistance as ${ }^{[10]}$.

$$
I=I_{s} \exp \left(\frac{q\left(\mathrm{VG}_{\mathrm{G}}-I R_{s}\right)}{n k T}\right)
$$

$R_{S}$ can be estimated from the $\operatorname{Ln} I=f\left(V_{G}\right)$ characteristics of the diode at high forward bias ${ }^{[7]}$. The $\operatorname{Ln} \mathrm{I}=\mathrm{f}\left(\mathrm{V}_{\mathrm{G}}\right)$ is, approximately, linear and $\mathrm{R}_{\mathrm{s}}$ is about $64 \Omega$ at room temperature. Figure 6 shows that the series resistance, $R_{S}$, decreases with the increase of the sample temperature and the reason of that, is the increase of carrier density with temperature.

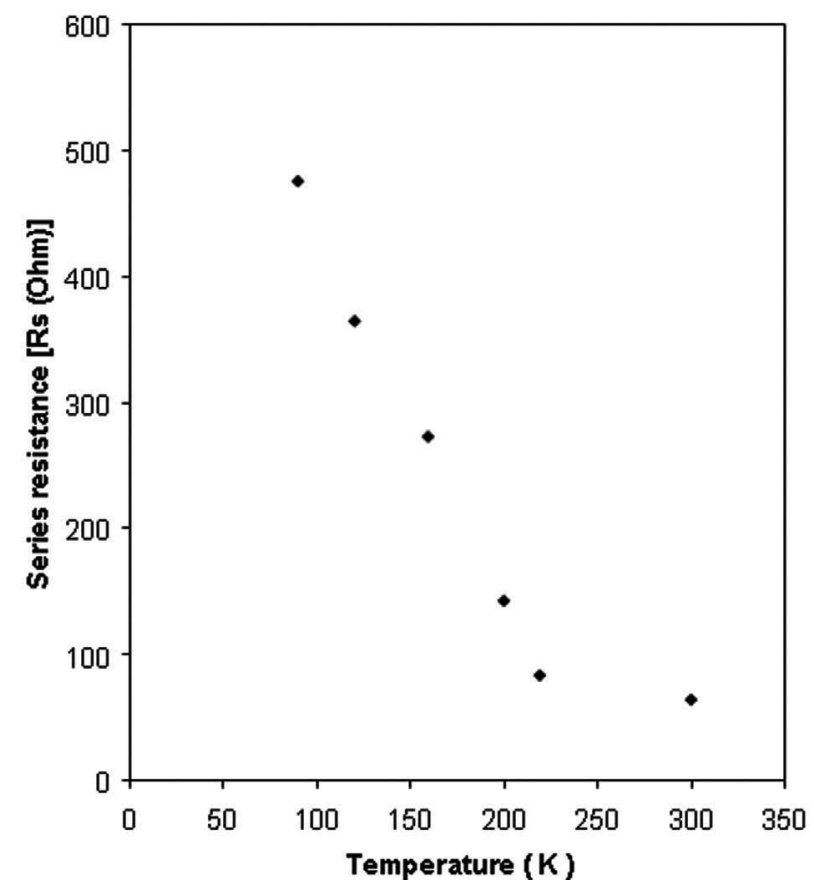

Fig. 6. Variation between series resistance with temperature of Au-GaN contact. 


\section{Conclusions}

The current-voltage at deferent temperature ranging from 90-300 K has been studied under vacuum. There was a departure from nonlinear behavior of the current to a linear one as temperature increases. It was noticed that the tunneling is the dominant mechanism of the leakage current. The saturation current, zero-bias barrier height, ideality factor, serial resistance, and the flat band barrier height were calculated $(8.3 \times$ $10^{-7} \mathrm{~A}, 0.66 \mathrm{eV}, 1.26,64 \Omega$ and $0.86 \mathrm{eV}$ respectively). The zero-bias barrier height and the flat band barrier height were increased with increasing temperature, but the ideality factor increases with decreasing temperature. Also the series resistance decreases with increasing temperature.

\section{References}

[1] Akazawa, M. and Hasegawa, H., High temperature sensing characteristics of a high performance $\mathrm{Pd} / \mathrm{AlGaN} / \mathrm{GaN}$ Schottky diode hydrogen sensor obtained by oxygen getting, Physica Status Solidi c, 5(6): 1959-1961 (2008).

[2] Jagadeswara, R., Verra, R. and Narasimha, R., Thermal annealing behavior on Shottcky Barrier Parameters and Structural properties of Au Contacts to n-type GaN, J. of Mat. Science, 19(4): (2008).

[3] Nakamura S., Pearton S. and Fasol, G., The Blue Laser Diode, Berlin: Springer: (2000).

[4] Alim, K., Doping and annealing of gallium nitride films, M. Sc. Thesis, Tuskegee University, Alabama (2003).

[5] Suzue, K., Mohammad, S.N., Fan, Z.F., Kim, W., Aktas, O. and Botchkarev, A.E., Electrical Conduction in Platinum gallium nitride Schottky diodes, J. Appl. Phys., 80(8): 4467-4478 (1996).

[6] Huang,Y., Chen, XD., Fung S., Beling C.D. and Ling, C.C., Experimental study and modeling of the influence of screw dislocations on the performance of $\mathrm{Au} / \mathrm{n}-\mathrm{GaN}$ Schottky diodes, Journal of Applied Physics, 94(9): 5771-5775 (2003).

[7] Akkal, B., Benamara, Z., Abid, H., Talbi, A. and Gruzza, B., Electrical characterization of $\mathrm{Au} / \mathrm{n}-\mathrm{GaN}$ Schottky diodes, Materials Chemistry and Physics, 85: 27-31 (2004).

[8] Osvald, J., Kuzmik, J., Konstantinidis, G., Lobotka, P. and Georgakilas, A., Temperature dependence of GaN Schottky diodes I-V characteristics, Microelectronic Engineering, 81: 181-187 (2005).

[9] Vesely, J.C., Shatzkes, M. and Burkhardt, PJ., Space-charge limited current flow in gallium nitride thin films, Physical Review B, 10(2): 582-590 (1974).

[10] Sze, S.M., Physics of Semiconductor Divice, New York: John Wiley (1981). 


\section{در اسة حر ارية لشريحة من مادة نتزيد الجاليوم الملتصقة بمعدن}

\section{سعيد سعد الأمير}

قسم الفبزياء، كلية العلوم، جامعة الملك عبدالعزيز

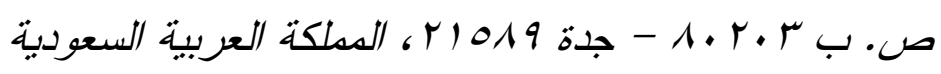

المستخلص. شريحة رقيقة من مادة نتريد الجاليوم GaN رسبت

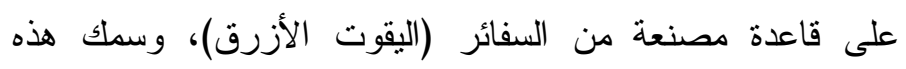

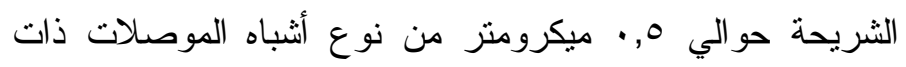

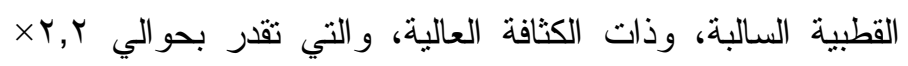

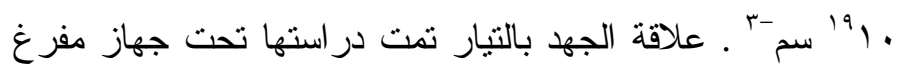

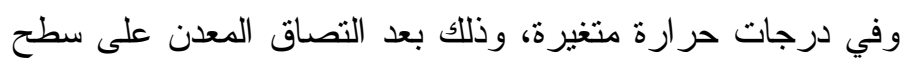

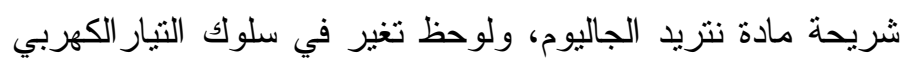

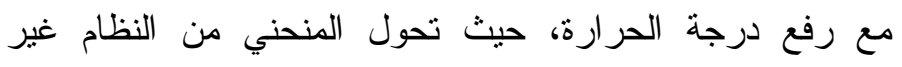

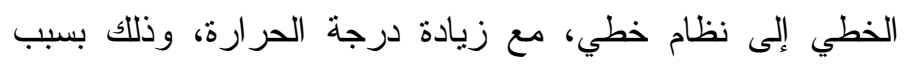

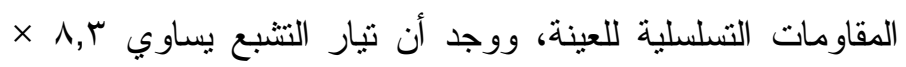

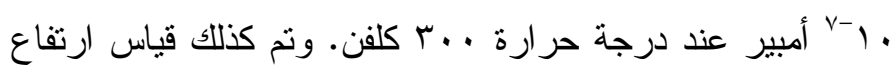

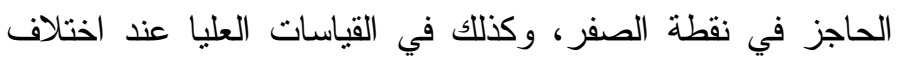

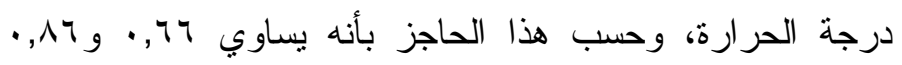
إلكترون فولت على التوالي. و أيضا نم حساب العامل المثالي لمنل

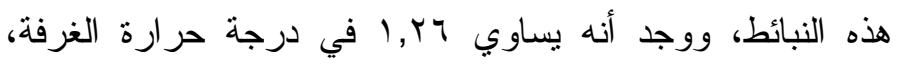

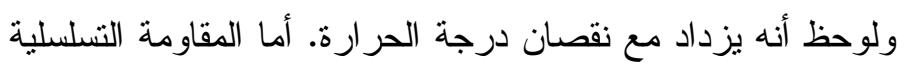
Rs 